\title{
An 'academic' dilemma: the tale of archives and records management
}

\author{
Elizabeth Shepherd
}

Department of Information Studies, University College London, UK

Elizabeth Shepherd is a Reader in archives and records management at University College London, where she has been MA programme director, Departmental Graduate Research Tutor and leads the research centre, ICARUS. She was a member of RAE2008, Library and Information Management Sub-Panel.

Corresponding author: Dr Elizabeth Shepherd, Department of Information Studies, University College London, Gower Street, London WC1E 6BT, UK. Email: e.shepherd@ucl.ac.uk

\begin{abstract}
This article discusses the development of academic research in the archives and records management field. It is argued that the field has faced a dilemma between educating graduates for work in a professional domain and developing robust research methods and frameworks for the emerging academic discipline. The article reports on some projects which have developed research frameworks and networks in the UK and internationally and considers some future directions for archives and records management research. In the light of the Research Assessment Exercise 2008, and in preparation for the Research Excellence Framework 2014, this is a good time to take stock of the progress made in this sub field of LIS and map its future strategic direction.
\end{abstract}

\section{Keywords}

Archives and records management; research; library and information science research; Research Assessment Exercise; Research Excellence Framework

\section{Introduction}

A dilemma tale is an African short story, the telling of which raises issues about conflicts of loyalty, proposes the need to choose a just response, and whose ending may be morally ambiguous or unresolved, leaving the audience to comment on the 
correct outcome. Dilemma tales should be both instructional and entertaining. ${ }^{1}$ This article recounts the journey which archivists and records managers in the UK have taken in the first decade of the $21^{\text {st }}$ century. It will reflect upon the dilemma which the field called 'archives and records management' has faced in having to choose between the two identities of being on the one hand, a profession, and on the other, an academic discipline. Perhaps the dilemma is a false dichotomy and we can excel as both a profession and as a discipline: the reader may judge at the end whether we have made the right choices.

The article addresses changes in archives and records management education and research in UK universities, which is a story about the building of a new academic discipline. It looks at some new structures such as the development of research groups in universities which have both contributed to and responded to the national policy and funding context, including the Research Assessment Exercise. The second part of the article discusses the findings of some research projects which have investigated ways of facilitating research in the discipline and which offer directions for the future.

\section{Building a new academic discipline: the issues}

More than 60 years have passed since archival education was established in English universities (Shepherd, 2009). Just after the Second World War, in 1947, three universities began to teach archives studies at graduate level. At Liverpool University, the newly appointed Professor of medieval history established a Diploma in the Study of Records and Administration of Archives. In Oxford, the Bodleian Library, Department of Western Manuscripts and the History Faculty evolved a training scheme for archivists. At University College London (UCL) the study of archives was established in the School of Librarianship. Sir Hilary Jenkinson, the so-called 'father of English archives', was instrumental in the beginnings of the programme at UCL. In his inaugural lecture to mark the launch of the London archives diploma he declared that 'the Profession of Archivist may be said to have arrived' (Jenkinson, 1947: 13).

What these early university programmes focused on was the training of archivists, recruiting historians and humanities graduates and ensuring that they acquired the necessary historical skills to enable them to act as 'the handmaidens of history'. They were taught palaeography, diplomatics, and archaic languages, together with the 
basics of arranging and listing archives, preservation, and, later, such things as records management and information technologies in archives. The teaching was about the archival skill set and their teachers were drawn from archival practice (for example, staff from the Public Record Office (PRO) held classes for students from UCL at the PRO in Chancery Lane, London). The academics appointed by the universities to teach archives had research interests in allied academic disciplines including medieval history, historical bibliography, and diplomatics. There was no concept that archives and records management could be a discipline in itself: one of the academics teaching in the 1960 s referred to the 'restricted nature of the subject'.

By the late 1990s a different view prevailed. Most of those being appointed to academic posts were professional practitioners, only a few of them were qualified to doctoral level when appointed, and although the concentration of the archival education programmes was still on practical skills, it was a very different skill set from the 1940s (now students were taught archival description, public access and use, standards, and digital records management). Research also began to have a higher profile as the new generation of faculty sought to establish their academic credentials.

However, professionals also started to ask questions about research into the discipline of archives and records management, why it might matter, and what value research added to their work, whether as academics or as practitioner archivists. They started to think about the 'mind-set' of the profession, as well as the 'skill set'. Thinking about 'why', as well as 'what' and 'how', reflecting on what research meant in a professional context and on ways in which research could be embedded into the discipline (Hare and McLeod, 1999; McLeod, 2008). Archival educators in other countries were also considering the role of research in the discipline, suggesting that it helped to build theories and models, that it developed the knowledge base and promoted critical enquiry, and considering the role of practitioner-led research (Craig, 1996; Gilliland-Swetland, 2000; Gilliland and McKemmish, 2004).

Eric Ketelaar (2000: 324), Professor at the University of Amsterdam, asserted that 'archival theory is despised and rejected by many practicing archivists' and suggested that in the Netherlands this could be traced back to the publication of the Dutch Manual by Muller, Feith and Fruin in 1898, which codified archival methodology 
before archival theory could develop. Ellis (2005) suggested that in the UK, the Manual of Archive Administration by Hilary Jenkinson published in 1922 similarly froze archival practice and left English archivists without a conceptual framework. As Ketelaar put it, we were winning the battle to provide day-to-day archival services, but without a research base we were in danger of losing the war to save the profession.

Within UK universities, research activities became increasingly important after 1992, when the 'binary divide' between universities and polytechnics was abolished and the first full-scale Research Assessment Exercise (RAE) ran, the results of which helped to determine the distribution of public funds for academic research. Research brought prestige and international reputation and it unlocked funding streams. Archives and records management was a professional applied activity: it was not an established academic discipline. None of the usual academic infrastructure needed for research sustainability existed in the UK for archives and records management. First, there was no research council for the arts and humanities to provide research grants until the Arts and Humanities Research Council (initially a Board) was established in 1999. Before then, research grants might be obtained from the Economic and Social Sciences Research Council (ESRC) or sometimes from the Leverhulme Foundation, and some research was funded by the British Library Research and Development Department. However, while some fundamental research was funded by the British Library, other projects were characterised as trivial, parochial, and lacking in the rigour which was demanded by the Research Councils (Feather, 2009: 175).

Secondly, there was no critical mass of researchers. Bright graduate students in archives and records wanted to become professional leaders not academics. There was no established career path in the universities for them to follow, in any case, since the subject was taught in a handful of UK universities, with one or two academic staff in each, who tended to remain in post for decades. There were thus very few academic or research associate posts, no post-doctoral fellowships and few doctoral scholarships in the field. A third issue was the lack of well established research methodologies for the field and of research collaboration, so that there were no established patterns for researchers to follow or research groups in which they could learn the necessary skills. Archives and records management had to borrow from other fields initially and adapt research methods to suit particular projects. Some 
research was closer to the humanities (such as studies of the history of the profession) which could adopt historical source-based approaches, while other research was akin to social sciences (perhaps using grounded theory), cultural studies, or to anthropology (using ethnographic methods, for example). New researchers could not easily identify research groups or collaborations to join, since few existed, making it difficult for them to get started.

Fourthly, there was little experience of rigorous peer reviewed academic writing in the discipline. Practitioner professionals felt no need to develop these particular skills, preferring to write case studies and project reports, although they became adept at writing successful project grant proposals for work-based projects which enabled them to unlock funding for collection description and digitization projects, including a number of successful national collaborative projects. Academics encouraged their Masters students to take a more rigorous approach to research and writing in their dissertations, and they sought themselves to influence the academic quality of journals, for example by editing and publishing in the Records Management Journal and the UK Journal of the Society of Archivists (McLeod and Hare, 2010). ${ }^{2}$ The orientation and quality of the journals in the field was part of a fifth concern, which was that journals, conferences and networks were usually professional rather than academic. Successful academics are expected to write in highly ranked, peer reviewed international journals and to be invited to give keynote lectures at prestigious academic meetings and conferences. Such events hardly existed for archives and records management and academics had to choose between spending their time building an academic reputation in an established field such as history, or talking to professionals which might be good for public engagement and knowledge transfer but was not rated highly in academic terms. Finally, unlike many other subjects, there was no learned society for archives and records academics, so they lacked a point of contact between themselves and had no focus for advocacy with university funders and policy makers.

However, the subject was largely unresearched, which gave academics an unusual opportunity to set the research agenda, to define and establish the field, to choose the research that was of most interest to different universities and individuals, and to work openly and collaboratively, avoiding the more competitive approaches necessary in 
other disciplines. Academics had to prove that the discipline was worthy of research, as colleagues had done in other countries, and, by addressing some of the systemic weaknesses discussed above, were able to open up a whole new discipline.

\section{Building a new academic discipline: some solutions}

By the turn of the $21^{\text {st }}$ century only about a dozen archives and records management academics worked in UK universities, so success in building the discipline could only come from working together. The first step was establishing an academic association in 2000, known as FARMER (Forum for Archives and Records Management Education and Research), which gave the group a name and an identity. The new association was founded on a twenty year tradition of informal annual meetings, but the more formal organisation enabled work to start on, for example, the development of strategic research priorities. FARMER obtained some AHRC funds for a research network, ARMReN, in 2006-2007 as part of which it organised research workshops, which attracted international delegates and speakers and raised the UK's profile abroad (ARMReN, 2007). FARMER was also able to link up with other regional and international groups, such as the North European Network of Archival Educators and Trainers (NAET, 2010) and the International Council on Archives, Section for Archival Education (ICA-SAE, 2010), which allowed it to work collaboratively with academics in other countries and regions on projects of common concern.

FARMER ran two national doctoral conferences, which for the first time brought together doctoral students and academics from UK universities to discuss their research, share ideas and give peer feedback and support. FARMER also ran two archival education conferences, the first in Aberystwyth in 2006 and the second in Oxford in 2010 with the theme 'Questions of trust? Archives, records and identities', both attracting international speakers (FARMER, 2010a). Such conferences provided a more formal academic framework for the discipline and the competitive call for papers and peer reviewing of conference outputs helped the discipline to develop academic rigour. There are other examples around the world: for example, the International Conference on the History of Records and Archives (ICHORA, 2010), now in its fifth iteration, has established a very high reputation for the quality of its papers, and the USA Archival Education and Research Institute (AERI, 2009) funded for four years from 2009 is a magnificent forum which brings together over 50 mainly 
North American doctoral students and faculty each summer for an intensive week, as well as providing funding for many doctoral candidates each year to undertake research in the field of archival studies in the USA. These associations, conferences and meetings are essential to the formal development of the academic discipline, as well as providing important informal mechanisms within which research can be nurtured. In due course, regional networks of archival educators across the globe, bringing us all to work together, should provide critical mass for collaborative work which it is difficult otherwise to achieve in a small discipline. Working together, forging our common identity and self-belief, has brought us a success which we would never have won as a scattered handful of individual scholars.

A second critical step for the UK was out of our hands, but was timely. When the research board, which became the Arts and Humanities Research Council (AHRC), was set up in 1999, it included a panel for the 'Information World'. This was the first time that a research council had explicitly included the archives and records management discipline within its remit, which was a great opportunity for the discipline to establish a research funding foothold. One of the very first AHRC large research awards was made to the School of Library, Archive and Information Studies at UCL for work on the LEADERS (2005) project (Linking Encoded Archival Description to Electronically Retrievable Sources), clearly situated in the archives and records field. Other major projects followed, such as AC+erm (Accelerating positive change in electronic records management) at Northumbria University (2010a). Funded projects provided the time and resources needed to undertake sustained research over an extended period, helped to build critical mass by providing research posts for new researchers and encouraged all those involved to learn from collaborative and cross-disciplinary research. The AHRC also provided scholarships for graduate study, both for professional preparation masters programmes and for doctoral study. As well as the Block Grant allocation of studentships to universities, which guaranteed a number of scholarships each year to students studying in particular fields including archives and records management, Collaborative Doctoral Awards (CDA) encouraged universities to develop projects which were supervised jointly with an employer (AHRC, 2010). Several universities secured CDAs, for example, UCL obtained two CDAs, both working with The National Archives, one on rethinking archival description in a digital environment (2007-2010) and the second 
considering the impact on archives of embracing greater user participation (20102013). These studentships allow academics and employers to be proactive about the direction of research. They are also essential if a pool of suitably qualified academics is to be built for the future expansion of the academy. It is now usual for academic appointments in the discipline to require doctoral qualifications as is the norm in other disciplines, but this can only be sustained if there is a supply of post-doctoral candidates with research interests in the field.

A third critical step was to ensure that the discipline was fully represented in the national Research Assessment Exercise (RAE), so that universities would see the value of the discipline (literally, since a good performance in the RAE resulted in raised levels of research income for the parent university in the following period). Four RAE cycles were run between 1992 and 2008, each on similar but not identical lines. Each was a peer quality assessment of submissions by university departments of their research activities, as submitted to one of the subject panels. One issue for archives and records management in this process was that they were situated in different departments in various universities (in history departments, in library and information departments, in the university archives service, in management, business and engineering faculties, and as separate archives studies centres). Archives and records management did not have a single type of departmental home and consequently had a rather unclear academic profile nationally. Since archives and records management was generally considered too small to stand on its own in the RAE, research groups were either not submitted, or were found in history, management or library and information science submissions, although the largest number were in this latter grouping. In the RAE 2008, most archives and records management research was submitted to the Library and Information Management subpanel.

Finally, and partly in response to the RAE frameworks, individual universities thought about how best to organise their research. For example, UCL set up a research group, ICARUS (2010), which brought together researchers interested in user access and description, community archives and identity, concepts of records, and information policy. It provided an umbrella for doctoral students, developing and managing funded research projects, individual scholarly work and joint publication. 
International experts (practitioners and academics) were invited to join as Associates or on the Management Board, and advise on research grants, act on project advisory boards, and give lectures and seminars, such as the annual Jenkinson Lecture. A monthly 'brown bag' research seminar has a catalyst speaker to set the subject and stimulate discussion. Even just getting together to talk informally about research progress is beneficial. None of this was revolutionary, but it does generate a much greater sense of facilitating, sharing and enabling and of a research community. Other universities have similar structures, such as the much larger Humanities Advanced Technology and Information Institute at the University of Glasgow, (HATII, 2010) and the Electronic Records Management group, part of a larger research grouping at Northumbria University (2010b).

Since 2000 archives and records management research in the UK has developed significantly. The formation of a research council which provides research project funding and studentships, the inclusion of the discipline in the national research evaluation exercise (RAE), the establishment of an academic association, FARMER, and the success of individual universities in developing their own research structures and programmes, combined with increased skill and experience of individual academics in research, has built a strong foundation for the future development of the discipline. However, this is just a beginning: what further steps need to be taken?

\section{Facilitating archives and records management research: future directions}

A small study, funded by the British Academy in 2006, investigated the state of archives and records management research, as a basis for identifying some possible future directions. Findings from that study, combined with work undertaken as part of the AHRC-funded ARMReN network project, discussions and considerations at FARMER meetings about research agendas and frameworks, and a research project run in 2010 by the International Council on Archives-Section for Archival Education, may provide strategic direction for the future.

\section{Mapping the research landscape for archives and records management}

A British Academy funded study, 'Mapping the research landscape for archives and records management', carried out in 2006 in UCL's Department of Information Studies, sought to gather information about academic and professional research 
projects in the UK during the period 1995-2006, to identify areas of professional practice with potential for research and establish how academics and practitioners in archives and records management used research findings in their work, and to identify research opportunities and some of the strengths and weaknesses in UK research, as a basis for improving the quality and quantity of research in the discipline. The aim was to create a map of the research landscape for the discipline in the UK. A Research Assistant executed four data collection activities. A literature review, using desk research, identified existing archives and records management research resources internationally. This was carried out in parallel with an analysis of a sample of UK MA thesis topics in archives and records management. Thirdly, six semi-structured interviews with archives and records management academics from Glasgow, Aberystwyth, Liverpool and London were carried out. Lastly, a Focus Group was held with a small number of records professionals to identify areas of existing practitioner research and of potential need.

The literature review suggested that there was a general perception among academia and professionals in the UK that research output was low, both in quantity and quality, when compared with the USA, Canada, and Australia and when compared with other information disciplines (McNicol and Nankivell, 2006). Eastwood (2000) in Canada argued that research was central to furthering and developing knowledge in archives and records management. UK professionals and researchers recognized the importance of research and the potential it had for improving the discipline, but as Ellis (2005) reported, many constraints impeded research. For example, she observed that MA courses in the UK focused more on imparting practical skills and less on research development. In the USA, Gilliland-Swetland's (2000) view was that archival schools which offered MA courses should not only seek to impart practical skills but should also convey knowledge, roles and philosophy of archives and records management, as well as promote and develop critical research thinking. Through this approach students will be better prepared to 'formulate their own way of looking at the world of archives and archival issues, and obtain a set of leadership skills, research tools, and vocabulary to query, understand, and advance the profession and the discipline.' Eastwood (2000) suggested that such an approach would not only lead to MA students seeing themselves as facilitators of research through the provision of access to records and archives but would enable them to realise that they were 
researchers in their own stead. As researchers, the students would be able to explore new ways through which they could improve and add value to their professional activities. In the UK, concerns about research development included the low total numbers of academics and full-time researchers (estimated to be about 12 individuals in 2006) at a time when increased MA student intake was leading to higher teaching loads. The effect of this was less time for research, a lack of research methods teaching to MA students, and difficulties for lecturers to obtain research leave (Ellis, 2000: 95).

Different views emerged in the UK interviews about the role of MA programmes: whether students have 'come here to be educated and intellectually developed so they can become researchers....or to acquire an intellectual framework that makes them professional practitioners. It is very hard to meet both communities' (BA, interview G4). The focus group argued that 'courses may prepare graduates adequately but may not prepare them well enough to become independent researchers.' This is compounded by the fact that even 'students do not expect that they are being prepared for research in these courses, rather they think they are being prepared for professional practice and not research' (BA, focus group, 8 Nov 2006). Focus group participants held the view that 'the profession will also be surprised if they felt that the schools were teaching students to become researchers rather than professional practitioners. Employers expect the graduate to undertake the practical aspects of archives and records management. The academics however feel that graduates should emerge from the courses with skills to undertake research so as to contribute to the profession's growth' (BA, focus group, 8 Nov 2006). This spells out the difficulties archives and records management programmes faced in trying to balance the teaching of research with practical skills.

The evaluation of MA dissertations produced by students of archives and records management noted a gradual improvement in the quality of the application of a chosen research methodology and in the framing of research questions, indicating perhaps that the students were receiving better research training. This analysis suggested that while research methods courses in themselves do not ensure that high quality dissertations are produced, where such courses were offered, students 
displayed better understanding of research methods and practices, could cite relevant research literature and were better able to evaluate the approaches they had deployed. Dissertations showed a general increase in awareness of a range of research methods and data collection techniques, beyond traditional humanities source-based research, which supported the increasing range of topics considered. Dissertation topics generally moved from a concentration before 2000 on traditional administrative histories and archival descriptions, towards those with a more theoretical approach, those taking a more critical stance and those addressing methodological issues. A number of the better dissertations, while displaying a good grasp of research principles, were produced by students who had practical experience in the field, suggesting a strong link between professional theory and practice. MA dissertations constituted the largest research contribution made each year, and yet they were not disseminated, were hardly available outside their originating departments and did not feed in to the published literature, since very few were ever re-written as journal articles or conference presentations. In general, the wider profession was not interested in research undertaken by new entrants to the profession and the universities did little to encourage publication.

The semi-structured interviews with academics and the focus group with practitioners sought to investigate the teaching of archives and records management research skills, their application in dissertation writing and in the work place. These interviews also sought to examine the interaction between research in an academic setting and that carried out by practitioners and the value and routes for the dissemination of research outputs. In 2006, the UK had seven archives and records management schools at the Universities of Glasgow, Dundee, Dublin, Northumbria, Liverpool, Wales (Aberystwyth) and London. All the schools sought to offer professional graduate qualifications and to carry out research, although the balance between teaching and research varied (for instance, Shepherd, 2006). One of the problems identified in the interviews was the range of research aspects, embracing that carried out by academics, by professionals in service, by consultants, and by policy bodies. Such a wide range in such a small discipline had perhaps led in the past to a lack of research rigour, doubts about quality and a lack of consensus about the definition and purpose of research. A view was expressed that there 'was a lot of poor research which is conducted with 
insufficient intellectual rigour...research methodologies are still not understood in certain quarters. Some researchers do not have a clue on how to select methodology or explain the methodology they select let alone decide on the literature review and use or justify research stance.' (BA, focus group, 8 Nov 2006). The absence of a research agenda, which had resulted in research being 'done on an ad hoc basis so as to fulfil requirements of the RAE and the expectations of the academic department', was identified as a problem (BA, interview W4) exacerbated by the prevalence of academics with professional, rather than academic research, backgrounds. In spite of increased MA student intake, enrolment for higher research (doctoral candidates) in archives and records management was low and concentrated in two or three universities at that time. About half of those students were international ones whose focus of research was often their home country, thus contributing less to UK research output. As a result, in the 1990s, UK academics had been appointed from a professional career track and not from an academic one and lacked research skills and experience themselves: 'a lot of the academics have come in from practice, so they don't have the research background, but I think that is changing' (BA, interview W4).

The interviews and focus group confirmed the discipline as essentially 'practitionerled', even in research, and suggested the strong need for academic leadership to emphasize the more theoretical and research aspects. One interviewee noted, 'predominantly the discipline has been practitioner-led. I mean it is a practice-led discipline and [in that way] it's no different from performing arts' (BA, interview G4), while another commented 'it [research] is not valued by the senior archivists in the UK. I think they have received extremely practical training and in a sense that is what they need.' (BA, interview W4). The practitioner focus was perceived as a major constraint: 'We have not put emphasis on agenda setting. What are the basic fundamental research problems that we need to address in archival science and records management?' (BA, focus group, 8 Nov 2006).

\section{ARMReN network project}

Following on from the British Academy funded study, FARMER obtained a grant from the Arts and Humanities Research Council Networks Scheme, for the two years 2006-2007, to run the ARMReN (2007) project, which supported activities to 
stimulate the UK research endeavour. The key aim of this project was to establish an enduring network to foster research in the academic discipline of archives and records management. In particular, it sought to improve the dissemination of archives and records management research among communities which could benefit, including researchers in other academic disciplines and information and cultural heritage professionals, to foster the development of younger academic researchers in the archives and records discipline, and to encourage the development of collaborative partnerships, both within the UK and internationally. It sought to do this through a series of research workshops held in London and Liverpool, expert speakers at 'Archives and History' seminars at the Institute of Historical Research in London, the creation and maintenance of an electronic information resource, and dissemination of results.

ARMReN ran three one-day research workshops. These were at the core of the network's purpose. The workshops attracted eminent international and national speakers, and were well attended, with over 30 delegates at each of the two London events and over 20 in Liverpool. The papers were a mixture of theoretical-academic and practitioner-focused. Delegates included academics and professionals, including from overseas (Canada, the Netherlands, Ireland, and Norway). The aim of seeking a broader cross-disciplinary discussion was not fully met: some speakers and a few delegates came from other disciplines (museum studies and anthropology) but the majority were from archives and records management. Perhaps the name of the network, Archives and Records Management Research Network, discouraged those from other disciplines from attending. The workshops were considered to be a great success by the delegates. One commented that 'the main strength of this workshop was the opportunity for discussion... something professionals don't always get the opportunity to do'. Others felt this was 'a good way to refresh thinking in this area and hear about how theory is applied on the ground in different institutions', 'useful as a means of familiarizing myself with current developments...At the end of the day I felt that I was once more up to date' and 'the thematic papers ... gave a very good insight into the most recent research on description in the UK environment. The parallel small group discussions were also an interesting way of seeing how practitioners related to the issues.' Generally, delegates found the workshops 'an enjoyable and useful event', 'interesting and thought provoking', 'stimulating and 
useful', 'informative and interesting. It gave a good overview of the kind of research which is taking place'. One delegate noted that he attended as a 'follow up from the [doctoral] research workshop in 2005, which prompted me to start my $\mathrm{PhD}$ ', while another was seeking "potential research areas which might benefit from a collaborative project with the National Council on Archives'. 'The workshop format was a good one for discussion and it would be great to see these workshops continuing.'

Delegates welcomed the discussion sessions which provided an opportunity to ask more specific questions and raise particular issues. Some of the themed discussions turned into expert seminars, for example, on documentation strategy led by Peter Horsman. A number of delegates attended for professional development in methodological and practical issues, rather than thinking about research. However, one delegate commented that "practitioners should be more involved in research and I was disappointed at the lack of show by other practitioners'. The predominance of young professionals and the attendance by doctoral students at the workshops fostered the development of younger academics and researchers, one of the Network aims.

Delegates made useful suggestions about follow up activities, noting that practitioners found it difficult to engage with and find out about research, even if they actively seek it out. They suggested the further development of the ARMReN webpages as a point of contact between practitioners and academic researchers, including a digest of articles and projects to promote collaboration, and establishing an email discussion list for ARM research through JISCmail, started subsequently as <armresearch@jiscmail.ac.uk>. They also wanted to see the workshops continued as a locus for examining practice-research relationships, perhaps in association with other partners. Actions proposed at the final workshop included establishing a blog to raise visibility and enable issues to be developed; developing an agenda for conferences for doctoral students and other researchers; greater regional consultation and activity; developing a national research agenda; developing the role of research in service organisations such as national archives; and managing the iteration between practitioners and research. 
ARMReN demonstrated the need for the research community nationally and internationally to have better routes to find and share information about research, perhaps by the creation and maintenance of a single gateway for access to research resources for the discipline. It identified this as an important follow up activity to help the network to become fully sustainable. Several previous attempts to promote online access to archives and records management research faced difficulties in generating high levels of participation and use. Although several universities supported institutional repositories which increasingly included outputs of archives and records management research, there is no subject repository for the discipline. FARMER sought to explore the possibility of developing one, or of fostering cross searching of institutional repositories for relevant research outputs, but thought that a full user needs analysis should first be undertaken to establish clearly the needs of the user base. Unfortunately, funds were not available for the project in 2007.

\section{FARMER research seminar}

Partly to help its members prepare for the imminent Research Assessment Exercise, FARMER convened a special seminar in Manchester at its annual meeting in January 2008, to which it invited Professor Eric Ketelaar of the University of Amsterdam, to talk about the Netherlands research strategy for archives and records management (Ketelaar, 2008). Caroline Williams, at the time Head of Research and Collections at The UK National Archives, introduced The National Archives's new research strategy (TNA, 2007). At the meeting, FARMER agreed to encourage the professional bodies to develop a statement about the role of research in the discipline, as CILIP and the Museums Association had already done. It also agreed to work on a draft research framework, drawing on existing knowledge about research activity, taking account of models from other disciplines and countries, and seeking to map and cluster existing research and analyse the gaps. Such a framework might later form an agenda for action in developing future research projects.

\section{International Council on Archives-Section for Archival Education (ICA-SAE)} research project

Individual universities have now developed extensive research programmes. In a few countries, there are emerging national programmes of research (for example the AERI doctoral project in the USA, the work done on the research strategy in the Netherlands, 
and the proposed FARMER research framework). However the future development of research is greatly hampered by a lack of knowledge of existing research activity: sharing of this knowledge is an essential part of the framework for building future strength in the discipline. The International Council on Archives (ICA) is in the unique position of offering an international umbrella for researchers. In July 2010, ICA-SAE commissioned a short investigation which sought to explore current practice in sharing research within the archive sector internationally, to consider the benefits of providing an online resource, and identify the key issues that ICA-SAE should consider in developing such a resource (Ray, 2010). The project explored the critical issue of sharing and developing knowledge of research in the discipline of archives and records management across national boundaries, as the basis of future research strategies.

The report was commissioned from UK-based consultant, Louise Ray, who identified a small group of fourteen stakeholders (academics, practitioners, and policy makers) to be interviewed about current practice and future needs. Ten of these responded to the invitation and were asked a series of questions, either through face-to-face contact or via telephone interviews. The sample group was chosen to represent individuals with an interest in archival research, training, practice and policy-making. The group included representatives working across four continents (Europe, Australasia, English-speaking sub-Saharan Africa and North America) to elicit a range of perspectives: however, it was recognised that these views were not necessarily representative of the wider archival sector, or indeed the whole archive research community. A larger survey with wider geographical reach could test the extent to which the findings are applicable beyond the sample group. The interviews were supplemented by desk research, reviewing websites publishing information about research projects and an examination of an ICA-SAE prototype research database, developed in an earlier project.

Almost all of the interviewees referred to their approach to accessing information about research as 'ad hoc' or 'haphazard'. The lack of inclusive structured routes for finding research data meant that there were concerns that information relevant to research, teaching, policy-making and practice could be missed even by the most diligent searchers. Existing access routes were not thought to deal effectively with 
language barriers, and these barriers hampered access to the broadest range of research. The report suggested that the most significant ways of publicising research within the archives and records management sector can be categorised in eight areas; journals and publications, conferences and conference papers, information about research projects online, e-lists and e-bulletins, personal contacts and word of mouth, networks, funding agencies, and related academic activity, but use of these methods was described as ad hoc. This research reflects findings about communicating knowledge by UK researchers more broadly (RIN, 2009) which reported that researchers disseminate their work through a range of routes and that 'the choices they make are underpinned by a number of interrelated motives beyond the simple desire to pass on their findings to those who may be interested in them. These motivations include the desire not only to maximise dissemination to a target audience, but to register their claim to the work they had done, and to gain peer esteem and the rewards that may flow from that' (RIN, 2009: 4). RIN (2009: 4) also noted that 'in deciding when, where and how to communicate their work, researchers may have to make choices between speedy dissemination to a desired audience, and less speedy publication in a high-status journal'.

Interviewees in the ICA-SAE research perceived significant benefits in the development of a shared online information resource for researchers, teachers, policymakers and practitioners. Based on the analysis of existing access to research and the possible benefits, the key attributes of any online resource were identified as being Inclusive, Accessible, Collaborative and Sustainable. In order to move towards the development of an effective web resource that has these essential attributes, some key questions that will inform the design and delivery of the site need to be considered. These include issues of quality control, levels of choice in the content provided, preferred languages for an international site and whether there is a need for a classification scheme for research. Some more technical aspects included the use of user-generating tagging or enhancement tools such as RSS feeds and e-digests. Management issues included whether access to the site should be free of charge, which organisations might work together in developing and sustaining the site, whether it should be done on a paid or voluntary basis and ICA-SAE's role in such a project. 
ICA-SAE continues to take an interest in research communication and networks and plans to do some follow-up work on the recommendations of the report in 2011-12.

\section{Research Assessment Exercise 2008 and Research Excellence Framework 2014}

In 2008 UK universities were preoccupied with the RAE, described by the Chair of the Library and Information Management Sub-Panel, John Feather, as 'a disciplinelevel peer assessment of the quality of research submitted by university departments, together with an assessment (partly metrics-driven but again largely informed by peer evaluation) of the research culture of institutions submitted' (Feather, 2009: 176). The definition of the discipline developed by the sub-panel for 2008 (RAE2008, 2006: 47) was

... disciplines concerned with the management of information and knowledge in all formats, namely librarianship and information science, archives and records management, and information systems. This may include: research on the generation, dissemination and publication, exploitation and evaluation of information and knowledge; information policy; the information society; information media; information literacy; systems thinking; systems development; knowledge management systems; information retrieval; preservation and conservation; impact assessment; and historical and cultural aspects of the disciplines. The sub panel also welcomes the submission of research into the learning and teaching process in the disciplines.

Feather has discussed the development of library and information science research in the context of the RAE, and many of his conclusions apply equally to archives and records management (Feather, 2009). In particular, the increasing professionalization of research which he identifies, bringing it 'closer to the main stream of academic research...than was the case 20 years ago', through the development of research questions, the use of appropriate methodologies, success in obtaining research council funding, and publication in peer reviewed scholarly journals, is similarly true for archives and records management research, although in our case the process has been an even more recent one.

Most departments active in research in archives and records management were returned to the Library and Information Management Sub-Panel in 2008, although some work in the discipline was either not returned or was returned to other sub- 
panels. The 21 submissions made to the sub-panel included 'a wide range of activity within the discipline, including information management, librarianship, archives, records management, knowledge management, and information systems' (RAE2008, 2009: 3). Although the discipline represented only a part of the sub-panel's work, and does not appear in detail in the sub-panel's subject overview report, nevertheless many of the more general remarks made there seem to apply to archives and records management. For example, there was 'evidence of a well-developed research culture in many departments... This included evidence of investment in postgraduate research to secure the future development of the discipline. In general, the sub-panel detects significant advances in the systematic and professional approach to research management across the discipline as a whole' (RAE2008, 2009). This is certainly true of archives and records management, where several universities have set up research centres which attract international scholars and generate high levels of research grant income. 'Significant developments in postgraduate research since 2001' are also reflected in archives and records management, where doctoral research numbers rose to a high of 21 in 2010, spread across seven universities, many of which have begun doctoral programmes within the past decade (FARMER, 2010b). Several of these doctoral students are supported by AHRC funding, in particular through the Collaborative Doctoral Awards programme. Archives and records management research seemed to have been well able to compete with more established disciplines in the context of the RAE.

Details of the next round of research assessment due in 2014, this time called Research Evaluation Framework (REF), are beginning to be announced. Four Main Panels will oversee the work of 36 sub-panels, including sub-panel 36, Communication, Cultural and Media Studies, Library and Information Management, which subsumes RAE2008 sub-panels 37 (Library and Information Management) and 66 (Communication, Cultural and Media Studies) (REF, 2010a: 13). The chairman of the sub-panel will be Professor Peter Golding, a sociologist who chaired RAE2008 sub-panel 66. Previously a Pro-Vice Chancellor for Research at Loughborough University, Professor Golding moved to Northumbria University in 2010. Sub-panel membership should be announced by the beginning of 2011. Although sub-panel scopes have not yet been defined, it is expected that archives and records management will mainly fall into the remit of sub-panel 36. 
One aspect of REF2014 which is expected to be different from previous assessment exercises is the inclusion of evaluation of 'the impact that excellent research has had on society and the economy' (REF, 2010b: 2). A pilot exercise aimed at testing 'the feasibility of assessing research impact, and to develop the method of assessment for use in the REF' (REF, 2010b: 2) in five subject areas across 29 universities was run in the latter part of 2010. It concluded 'that it is possible to assess impacts arising from research in these disciplines' (hardly a ringing endorsement) and made 19 recommendations about how to define research impact, the kinds of evidence of impact which might be acceptable, and how REF panels might assess impact, including proposing two criteria for assessment, 'reach' and 'significance'. The proposal to allow one impact case study per ten academics could well mean that small departments (including almost all those researching in archives and records management) would only have one or two such statements accounting for as much as $20 \%$ of the REF profile. However, since the discipline, in common with most of the information field, has well established public engagement programmes and longstanding and close connections with professional bodies, the connections between research and the public benefit may be easier to discern than in some academic disciplines.

\section{Conclusion}

So to return to the dilemma the article began with. Should our allegiance be to the archives and records management profession or to the research-led discipline? Academics have made a conscious choice to move away from simply educating the new professionals and chosen to privilege research and the academic discipline. Really, there was no alternative: if professional education is to thrive, it must be delivered in a research-led university. In fact, any dis-unity between delivering professional skills and helping our students to think conceptually should be a positive and creative one. Together we have created an academic discipline in the UK and contributed to a confident and dynamic profession, so perhaps the dilemma is a false dichotomy, perhaps it is possible to do both. However, now there is something new to be achieved, which is to break down the carefully constructed boundaries around our discipline and open it up to the critical scrutiny of other disciplines: REF2014 will 
certainly be an opportunity to see how robust the discipline core of archives and records management is and how much we can learn from other, more established, disciplines and they from us.

\section{Funding}

This work was supported by the Arts and Humanities Research Council (research network, grant number 119774); the British Academy (grant number SG 44249); and the International Council on Archives (grant number P2009 SAE3).

\section{References}

AERI (2009), see http://aeri.gseis.ucla.edu/index.htm , accessed 25/03/2010.

AHRC (2010), Collaborative Doctoral Awards, see

http://www.ahrc.ac.uk/FundingOpportunities/Pages/CollaborativeDoctoralAwards.asp $\underline{\mathrm{x}}$, accessed 25/03/2010.

ARMReN (2007), see http://www.ucl.ac.uk/infostudies/research/armren/, accessed 25/03/2010.

Craig, BL 'Serving the truth: the importance of fostering archives research in education programmes, including a modest proposal for partnerships with the workplace' Archivaria 42 (1996): 105-117.

Eastwood, T 'Archival research: the University of British Columbia experience.' The American Archivist 63:2 (2000): 243-257.

Ellis, M 'Establishing a research culture for archive administration in the UK', Education for Information, 23 (2005): 91-101.

FARMER (2010a) conference webpage, at https://www.ucl.ac.uk/infostudies/research/icarus/farmerconference2010/ , accessed 25/03/2010.

FARMER (2010b) email survey circulated by Caroline Williams, 26/03/2010.

Feather, J 'LIS research in the UK: Reflections and prospects', Journal of Librarianship and Information Science 41 (2009) 173-181.

Gilliland-Swetland, A 'Archival research: a 'new' issue for graduate education' American Archivist 63 (2000): 258-270.

Gilliland, A and McKemmish, S 'Building an infrastructure for archival research', Archival Science, 4:3-4 (2004): 149-197. 
Hare, C and McLeod, J 'Developing a research profile: a case study from the UK', Records Management Journal, 9:3 (1999): 215-229.

HATII (2010), see http://www.gla.ac.uk/hatii/ , accessed 25/03/2010.

ICARUS (2010), see http://www.ucl.ac.uk/infostudies/research/icarus/, accessed 25/03/2010.

ICA-SAE (2010), see http://www.ica-sae.org/ , accessed 25/03/2010.

ICHORA (2010), see http://www.liv.ac.uk/ichora5/, accessed 25/03/2010.

Jenkinson, Hilary The English archivist: a new profession, (London: H K Lewis, 1948)

Ketelaar, F 'Archivistics research saving the profession' American Archivist 63

(2000): 322-340.

Ketelaar, F (2008), Netherlands research strategy, unpublished, see

http://cf.hum.uva.nl/bai/home/eketelaar/research.html

LEADERS (2005), see http://www.ucl.ac.uk/leaders-project/ , accessed 25/03/2010.

McLeod, J 'Records management research - perspectives and directions', Journal of the Society of Archivists, 29: 1 (2008): 29-40.

McLeod, J and Hare, C 'Development of RMJ: a mirror of the development of the profession and discipline of records management' Records Management Journal, 20:1 (2010): 9-40.

McNicol, S and Nankivell, C The LIS research landscape: a review and prognosis. At <http://www.ebase.uce.ac.uk/cirtarchive/projects/past/LISlandscape_final\%20report.p df>, accessed 03/03/06.

NAET (2010), see http://www.naet-europe.org/networkwelcome.html , accessed 25/03/2010.

Northumbria University (2010a), AC+erm, see

http://www.northumbria.ac.uk/sd/academic/ceis/re/isrc/themes/rmarea/erm/, accessed $13 / 05 / 2010$.

Northumbria University (2010b) Electronic Records Management, see

http://www.northumbria.ac.uk/sd/academic/ceis/re/isrc/themes/rmarea/ , accessed 25/03/2010.

Ray, L, ICA SAE: Archival research and researchers. A short report by Louise Ray for the Section on Archival Education and Training: International Council on Archives (unpublished, 2010).

Research Evaluation Framework, REF2014 Units of Assessment and Recruitment of Expert Panels (2010a), at 
<http://www.hefce.ac.uk/research/ref/pubs/2010/01_10/01_10.pdf>, accessed $30 / 11 / 2010$.

Research Evaluation Framework, Research Excellence Framework impact pilot exercise: Findings of the expert panels (2010b), at

<http://www.hefce.ac.uk/research/ref/pubs/other/re01_10/> accessed 30/11/2010.

Research Assessment Exercise, RAE 2008 Panel Criteria and Working methods:

Panel I (2006), at <http://www.rae.ac.uk/pubs/2006/01/>, accessed 13/05/2010.

Research Assessment Exercise, RAE 2008 Subject Overview Reports 137 Library and

Information Management (2009), at <http://www.rae.ac.uk/pubs/2009/ov/>, accessed $13 / 05 / 2010$.

Research Information Network (RIN), Communicating Knowledge: How and why UK researchers publish and disseminate their findings (British Library, 2009).

Shepherd, E 'Developing a new discipline- UCL's contribution to the research and teaching of archives and records management' Aslib Proceedings: New Information Perspectives 58:1/2 (2006): 10-19.

Shepherd, E Archives and Archivists in $20^{\text {th }}$ Century England (Farnham, Surrey: Ashgate, 2009).

The UK National Archives (TNA), A Research Policy and Strategy for The National Archives (2007), at http://www.nationalarchives.gov.uk/documents/researchstrategy.pdf , accessed 13/05/2010.

\section{Endnotes}

\footnotetext{
${ }^{1}$ This article started life as a research colloquium paper given at the University of Toronto in November 2009 when the author was a Visiting Professor in the Faculty of Information.

${ }^{2}$ Both journals were recently awarded rank of A by the Australian Research Council Research Excellence Research Evaluation journals list, see www.arc.gov.au/era/era_journals_list.htm, and the JSA was ranked A in the European Reference Index for the Humanities, see http://www.esf.org/research-areas/humanities/erih-european-reference-index-for-the-humanities.html , both accessed 25/03/2010.
} 